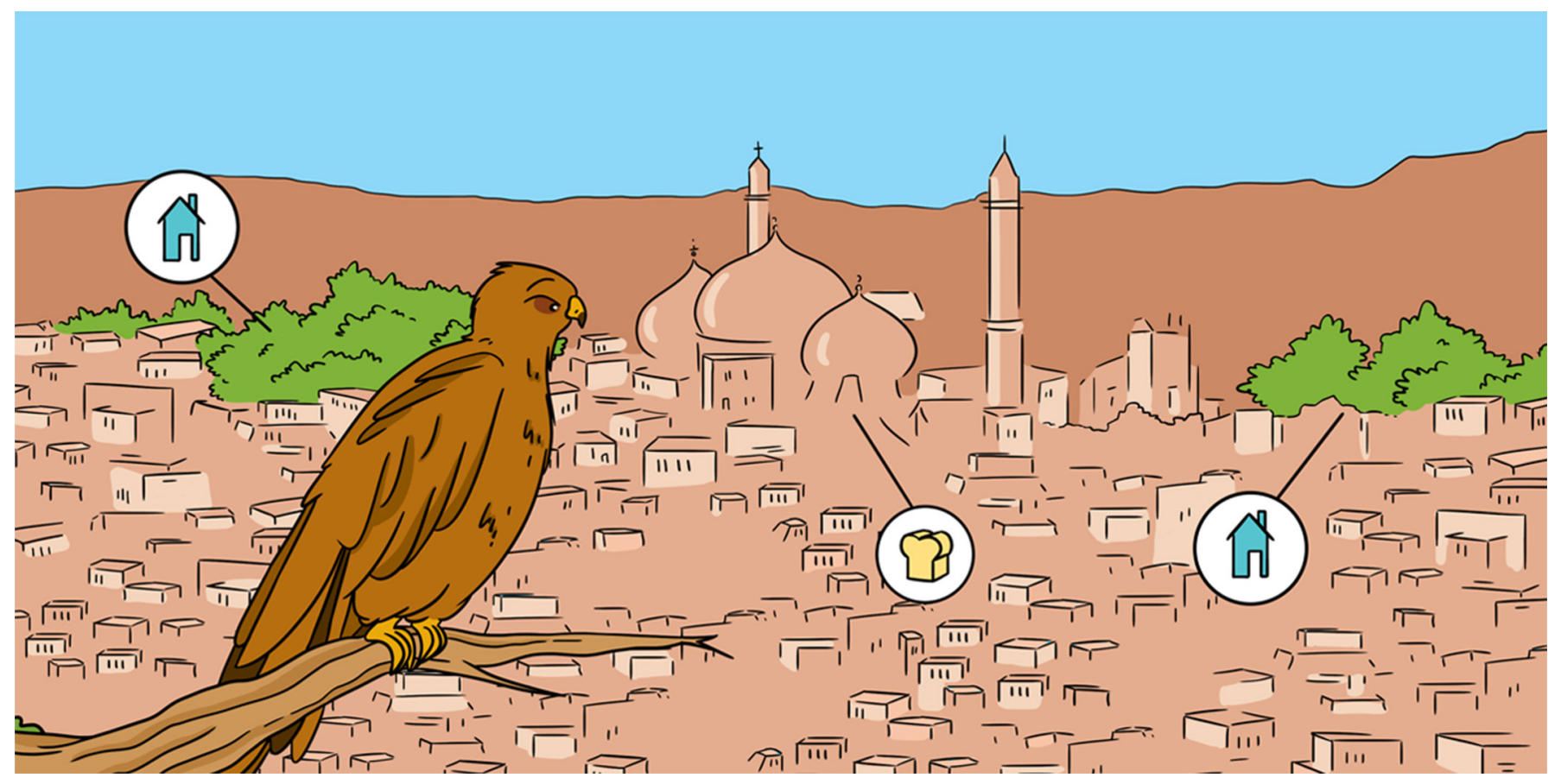

\title{
CITIES: HOW DO SOME BIRDS THRIVE THERE?
}

\section{Nishant Kumar ${ }^{1,2,3^{*}}$, Urvi Gupta ${ }^{2}$, Yadvendradev V. Jhala ${ }^{2}$, Qamar Qureshi $^{4}$, Andrew G. Gosler ${ }^{1,3,5}$ and Fabrizio Sergio ${ }^{6}$}

${ }^{1}$ Department of Zoology, Edward Grey Institute of Field Ornithology, University of Oxford, Oxford, United Kingdom

${ }^{2}$ Department of Animal Ecology and Conservation Biology, Wildlife Institute of India, Dehradun, India

${ }^{3}$ Mansfield College, University of Oxford, Oxford, United Kingdom

${ }^{4}$ Department of Population Management, Capture \& Rehabilitation, Wildlife Institute of India, Dehradun, India

${ }^{5}$ School of Anthropology and Museum Ethnography, Institute of Human Sciences, Oxford, United Kingdom

${ }^{6}$ Department of Conservation Biology, Estación Biológica de Doñana-CSIC, Sevilla, Spain

\section{YOUNG REVIEWER:}

LUANA

AGE: 14
Do you know that most humans now live in cities? This has caused a lot of trouble for many animal species. But a few opportunistic animals, like crows and pigeons that you commonly encounter in cities, benefit from dense human habitation. How does a very urbanized, paved, and populated landscape manage to support enormous flocks of birds in tropical cities? This is mostly unknown for urban birds like me: the Black Kite Milvus migrans. Researchers studying me in Delhi show that I depend on the food provided by humans and I prey on other common urban animals, such as pigeons and rats. The researchers of this article looked at the food that Muslims in the Indian subcontinent ritually offer kite birds and the impact these meat offerings have. Their analyses show that kite birds take cues from human activity, preferring densely populated areas in the city, with trees capable of holding a large nest, or 


\section{ECOSYSTEM}

The functional units of nature, comprised of living organisms (plants, animals and microbes) in a particular area, in conjugation with the nonliving components of the interacting system.

\section{VERTEBRATES}

Animals with a spinal cord surrounded by cartilage or bone.

\section{road configurations that allow for easy access to human waste and ritual food.}

\section{ABOUT ME}

Do you know that many animal species take care of their young ones, much like humans? Humans have, however, singularly dominated the planet for thousands of years and more recently devastated most ecosystems. This is typically visible when looking at the steady increase of built-up spaces, such as cities. Within only a few centuries, humans have depleted (by weight) almost $99 \%$ of vertebrates, either through hunting or deforestation [1]. Despite this, there are a few animal species that take advantage of garbage-based food and their populations can also reach high numbers. Humans often see such urban exploiters as pests that occasionally cause trouble or damage properties.

I am one such species. Frequently misidentified as an "Eagle" by city-dwellers in India, kites successfully live alongside humans, opportunistically seeking the availability of food from human generated garbage. Kite birds are reported to be one of the most common and successful birds of prey in the world. Black Kites Milvus migrans (Figure 1) are found throughout Eurasia, Africa, and Australia. They almost exclusively live in villages, towns, and cities in India [2]. In Delhi, where kites primarily build their nests on trees, religious kite-feeding practices also provide food. Are you aware of the centuries-old religious Islamic practice of feeding meat scraps to kites for blessings, and to seek relief from sins [3, 4] (follow the video link)? People of Islamic faith live in concentrated and well-defined areas of Delhi (hereafter "Muslim colonies") (Figure 2). Researchers have shown that enormous food-subsidies may explain Delhi's capacity to host so many urban animals [2].

I must stress that there are very few studies that focus on the impact of increasingly built-up spaces in previously non-human populated tropical regions. Most of this urban change is taking place closer to the equator [5]. Animals that are found in these cities play an important role in people's sense of connection with nature. They also remove tons of decaying garbage from the streets and provide a vital sanitary service for humans. One way to address the lack of knowledge on animals that live in cities and villages is researching their choice of suitable living areas and how human activities make cities a useful habitat for animal species. A group of researchers led by Nishant Kumar studied how a parent kite pair identified an urban space in Delhi to live in.

\section{WHAT DO RESEARCHERS EXAMINE WHEN STUDYING A COMMON URBAN BIRD?}

What prompted these researchers to study the ecological aspects of a common species? Citizens often assume "obvious roles" for 
Figure 1

(A) An urban Black Kite Milvus migrans govinda breeder with a twig in its beak is an

opportunistic predator that capitalizes on human food subsidies. Photo Credit: F Sergio. We fixed GPS platform terminal transmitters on a few breeding kites to understand their movement with respect to the distribution of food resources. Photo Credit: U Gupta. (B) A view from a Black Kite nest on a telephone-

tower in Delhi. A

heterogeneously developed city needs a multitude of strategies for opportunistic acquisition of urban resources. These strategies are fine-tuned, collectively, on local habitat structure and human activities that provide edible-waste and site-specific ritualized meat feeding. Photo Credit: L Narayan.

\section{RAPTOR}

Birds of prey.

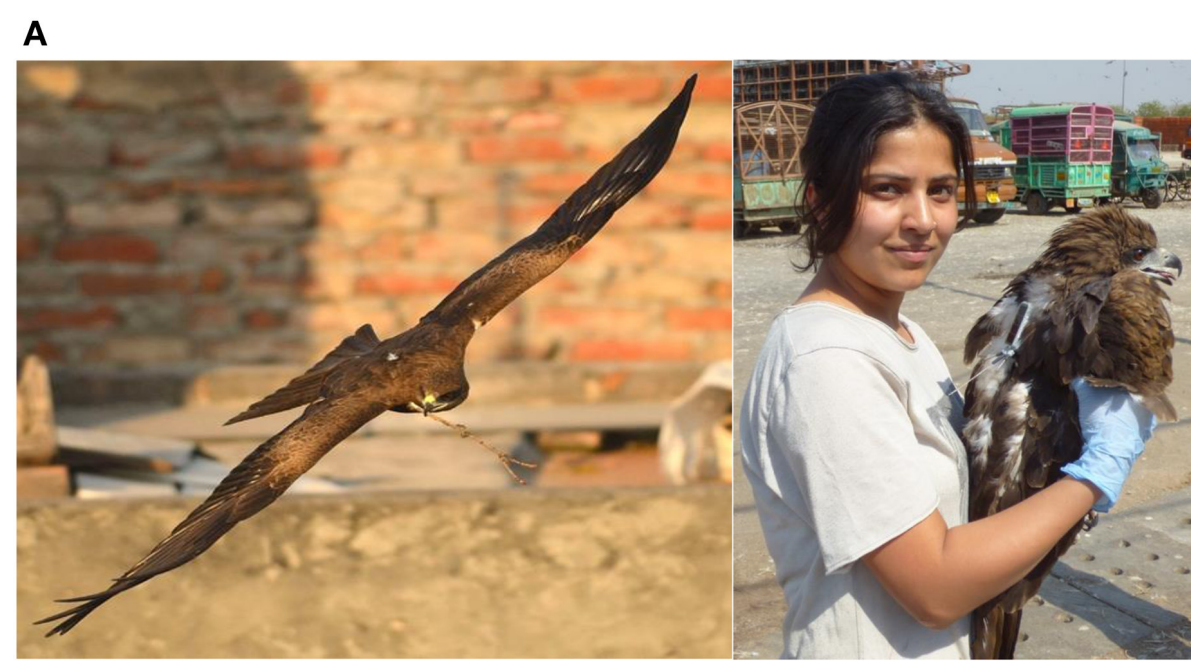

B

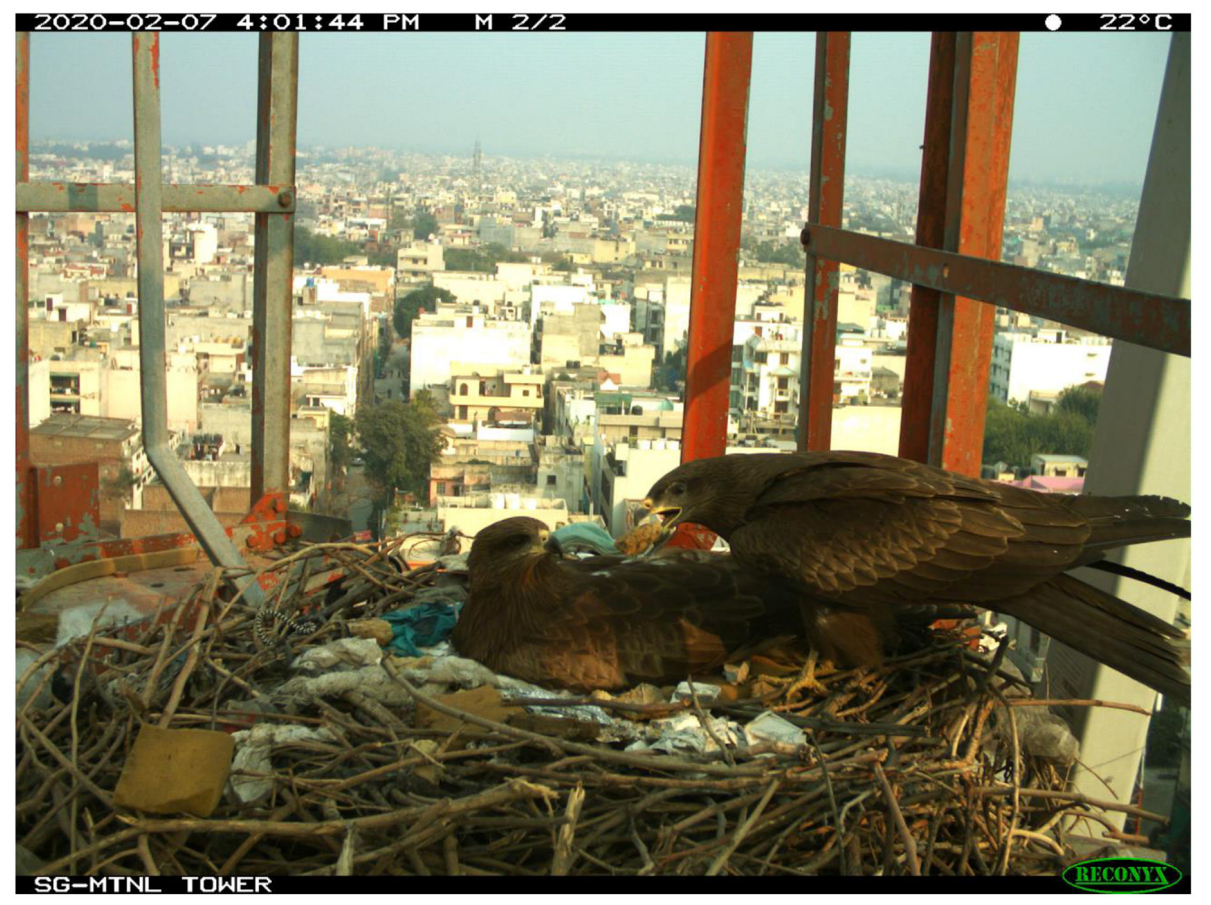

Figure 1

urban species, based on occasional observations or common sense. Interestingly, for the citizens of Delhi, and even for Kumar himself, the idea that a (large) raptor could nest in huge numbers within a city was unimaginable. Kumar's initial idea of a raptor was a fierce eagle that breeds in some remote, pristine forest, in small numbers, much like tigers. But reality often challenges human simplifications, and this speaks volumes about the wonders and actual machinery of nature waiting to be unraveled.

Once the team noticed sharp variations in the density of kite-nests, they systematically studied the number and productivity of nests between 2013 and 2016 at 24 sampling-plots, each of 100 hectares. These plots covered most of the possible urban settings within Delhi, 
Figure 2

Schematic depiction of the major difference between the spatial proximity of mosques (depicted in red, with Islamic symbol) to (A) a sampling unit, the National Zoological Park, and (B) a random location chosen by the computer in Delhi. Black Kites Milvus migrans capitalize on ritual meat tossing near mosques which were less likely to be found in the vicinity of a random location, implying their importance for kites' habitat preferences. Credit: Google Maps.

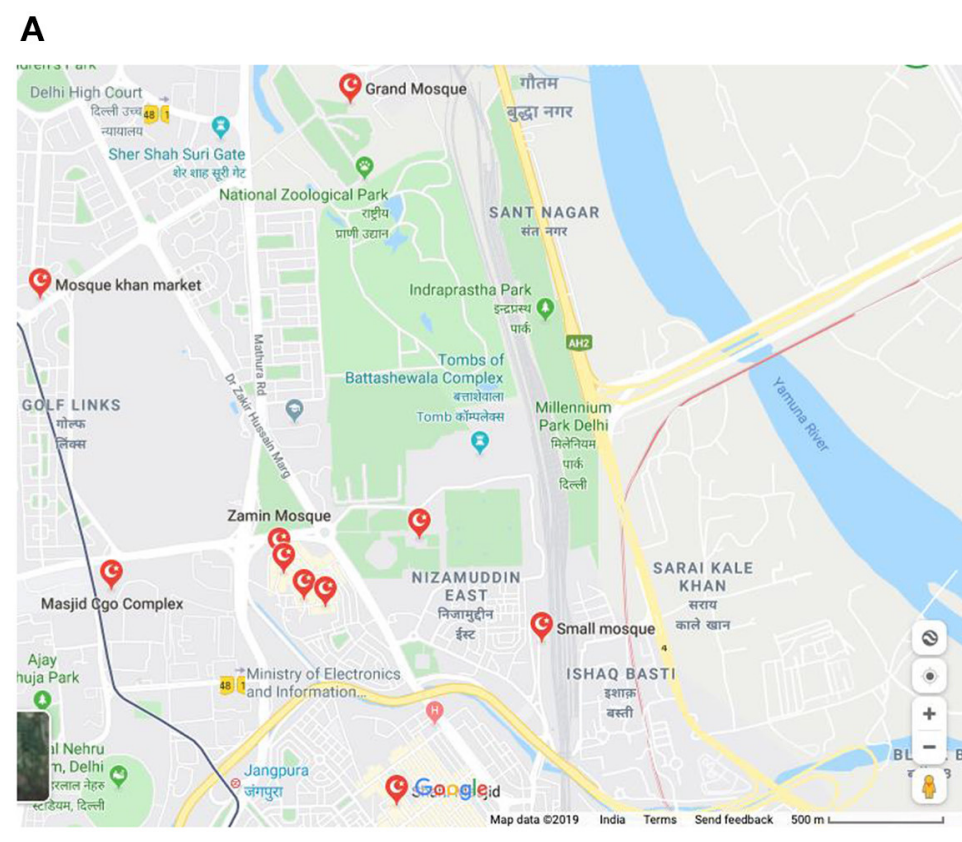

B

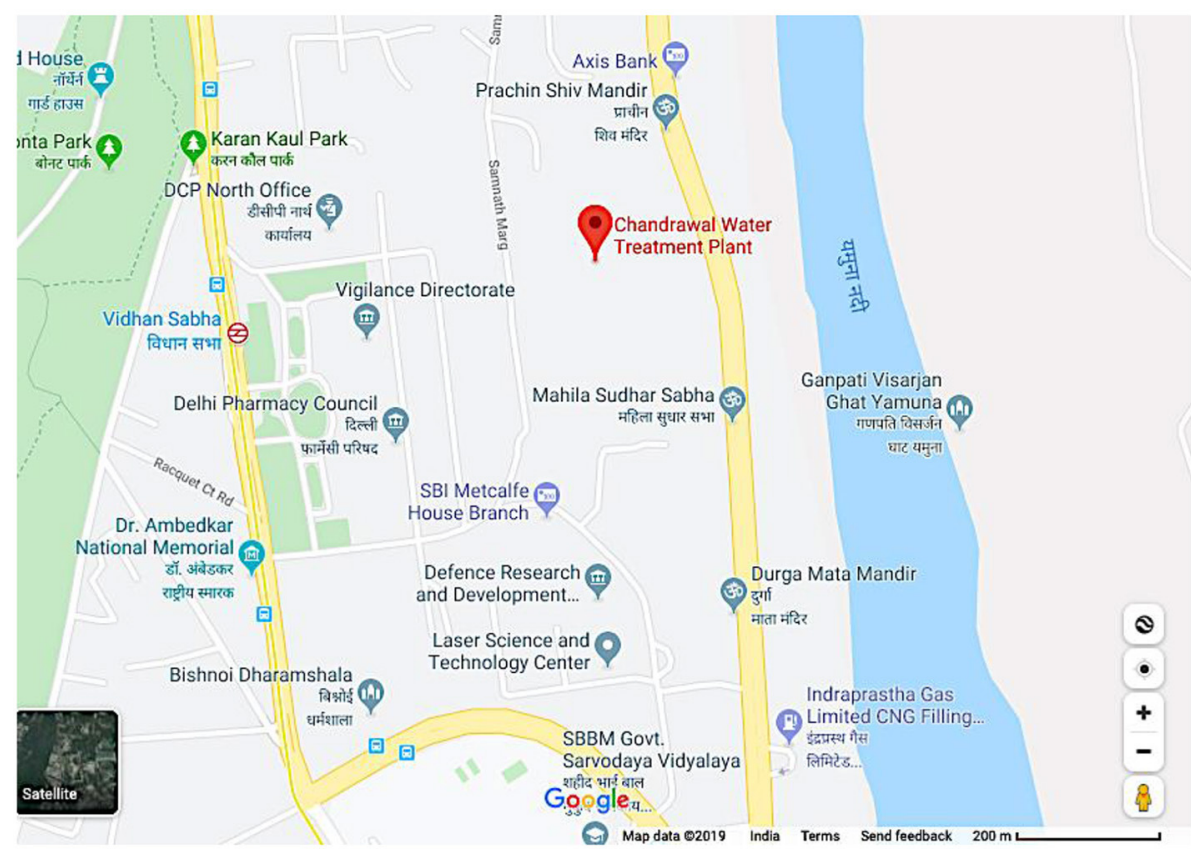

Figure 2

from semi-natural to extremely built-up sites. This resulted in a sample of 154 nests, checked every 7-10 days until they had chicks of at least 45 days, i.e., ready to fly and become fledglings. For each nest, the effort provided data on the number of young birds that were successfully raised until the flight-stage.

Now, considering that parent kites strategically choose a nesting-site, one would expect successful breeding-investment. Logically, such a strategy should simultaneously take into consideration the proximity 


\section{VARIABLE}

An attribute that describes a person, place, thing, or idea to reliable food sources and safety from potential predators and harsh weather. Researchers had to imagine what a city would look like to me from various altitudes, much like the outer view during the takeoff or landing of an airplane. Quite similarly, while flying at different heights, birds notice and choose from apparent features of a landscape. Researchers also considered variables to represent human socio-cultural activities, such as the religious ceremonies that provide kites with food and other resources.

In particular, researchers understood my nesting-habitat selection criteria within different developed pockets of a megacity. A typical way to determine such selection criteria is a comparison of actual nest locations (154) within the 24 sampling study plots, with a matching number of locations randomly chosen by a computer program (ArcGIS, a computer program for geographic analysis, i.e., a Geographic Information System, also called a GIS). At each computer-generated random-location, researchers selected the nearest tree or tower judged capable of supporting a kite nest. Logically, researchers expected kites to be choosy and thus they expected the site-based properties considered important for kites to differ significantly between actual nest locations and computer-generated random-locations. Researchers were additionally helped by remotely available data from a few kites that were carrying GPS-transmitters (transmitters that, once placed on a bird, record its location every few minutes, just as your mobile phone does) and confirming site-based properties important for kites, such as a circular area made up of a $500 \mathrm{~m}$ radius, frequently explored around the nest (called a "breeding territory") (Figure 1A). Kites regularly visited ritual feeding sites near mosques with very deliberate, directed journeys.

The site-based properties that allowed for comparisons of nest-locations with random points were primarily of three types: (a) at or around the nest level, e.g., the tree species and height, area of the woodlot around the nest, intensity of human street use around the nest, and the proximity to water and a waste dump, (b) within $500 \mathrm{~m}$ radial area around each nest and random site, such as the urban architecture or extent of tree cover and the built-up space, local density of buildings or roads, and (c) at each nest and random location, they also collected representative spatial data for ritual feeding activities, such as the proximity to large Muslim colonies. Further, at each nest or random location, the focal tree's situation with respect to surrounding trees was defined important in the following increasing order: an isolated nesting tree $<$ in a linear roadside avenue plantation $<$ within a park or woodlot. Researchers also classified the nests or random locations in two categories, depending on a high or low amount of edible food-waste (Figure 2). 
Figure 3

A broad analogy can be found in the work of a readymade garment tailor and a

field-researcher who starts a new research on a species. Both use models to test the fit: a tailor uses wooden-models to stitch clothes of various sizes, while a researcher uses mathematical-models that help them choose from the set of propositions (hypotheses) about the ecological criteria, as observed in the field. Sketch credit:

Poonam Pal.

\section{HYPOTHESIS}

A suggestive idea to explain phenomena under observation.

\section{ALGORITHM}

A set of rules that must be followed when solving a particular problem.
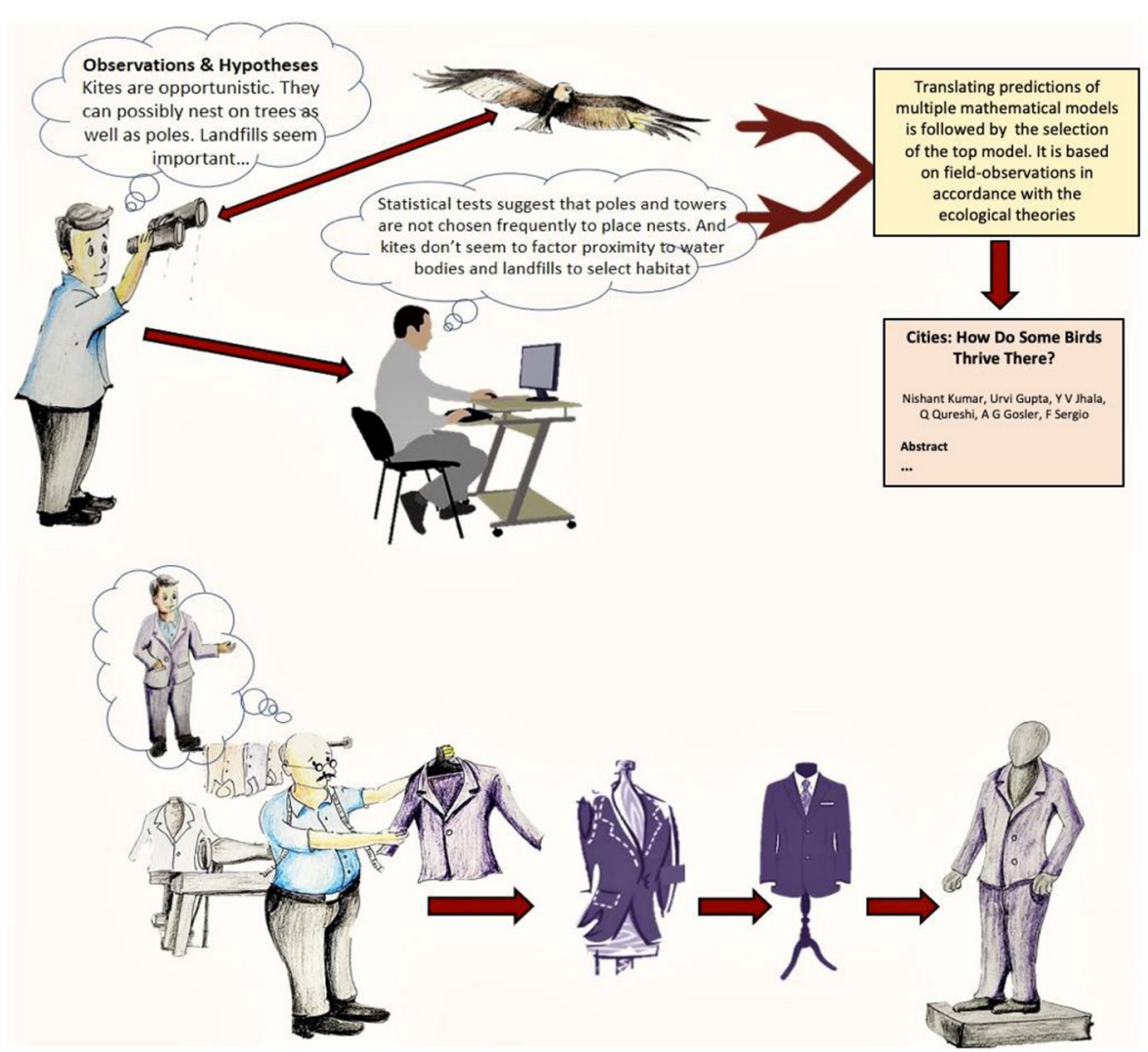

Figure 3

\section{HOW DO RESEARCHERS INVESTIGATE MY PREFERENCES?}

You must have observed clothed, human-like mannequins in clothing stores. Do you know that regular tailors stitch clothes for unknown buyers? They actually make use of similar "wooden-models" of various size categories (small, large, extra-large, etc., Figure 3) to stitch garments. Much like the tailor who stitched the readymade shirt you are wearing, a researcher who begins an ecological study is unaware of the preference criteria of non-human organisms. Considering that humans cannot look into my (kite) mind, field-researchers make meticulous observations to prepare a set of guiding propositions called hypothesis with respect to kite activities (Figures 1, 2). Subsequently, using data, they test the validity of these propositions using statistical programs and various "mathematical models" which are expected to best reflect my urban ecology. Ultimately, the research team arrives at the simplest final model that adheres well with the real, on-field observations on kites. Researchers validate such models using mathematical algorithms to reflect bird choices. Models inform why certain urban choices by the experienced and dominant breeding-kites make them more successful parents (Figure 3). 
BROODING/

INCUBATION

Acts of sitting on eggs or chicks by the female bird to maintain uniform heat and humidity.

\section{ADAPTIVE/} ADAPTATION

An evolutionary process where populations of a species become better suited to their habitat.

\section{WHY DO KUMAR AND COLLEAGUES' MATHEMATICAL MODELS STAY JUSTIFIED?}

Living in cities is a challenge for non-humans. Most of us kites build nests on trees, but not all trees have kite nests on them. This is because we "choose" to live in certain habitats. During incubation and initial brooding, the female kite is restricted to the nest for about 2 months. During this time the male takes charge of feeding the whole family. Researchers found that we avoided areas in the city that are contiguously built-up. We are more likely to identify nesting-habitat in safe clusters of trees in a park or woodlot that allow easy access to food coming from garbage piled informally on roadsides, and ritual offerings of meat within densely populated Muslim colonies. In addition, those among us that could breed in the areas with a greater extent of tree-cover in proximity to the sites of ritual feeding managed to raise more young-kites. We would, of course, like to identify habitable patches that are simultaneously associated with ample tree cover near multiple, large Muslim colonies. Thus, researchers defined this strategy of exploiting food near humans to be adaptive/adaptation, considering it was associated with higher nesting-success. The simplest and most-accurate mathematical model was based on 4 years of data, and observant-researchers (Figures 2, 3). In a way, the variation of food availability across the city was uniquely tied to complex human themes, which included (1) the complex history of Muslims in India; (2) planning of refuse disposal and urban-constructions useful for kites; and (3) cultural and religious practices.

People have an innate love for living creatures called Biophilia (bios: living; philia: love of) that is further diversified by religious beliefs in South Asia, where animals are considered as God's vehicles, or messengers from God. Like any megacity, Delhi will witness rapid change in the coming decades in terms of structure, management, and culture [4, 6]. Kumar and his colleagues have noticed the poor prevalence of the meat offering practice in youngsters, a generational shift that will eventually alter cultural tolerance for backyard-biodiversity [3]. In particular, our dependency on ritual feeding could be seen as a local uniqueness that connects citizens with nature and is thus vital research that should actively be promoted.

\section{AUTHOR CONTRIBUTIONS}

NK and UG led the writing of the first draft. All authors contributed to aspects of preparation and writing of the paper and approved the final version. 


\section{ACKNOWLEDGMENTS}

We thank Dr Becky Thomas, Ester Dias, Hedwig, the anonymous mentor and Luana for constructive comments that greatly improved the manuscript, and Ujjwal Kumar and the Director, Dean and Research Coordinator of the Wildlife Institute of India for materials, encouragement and advice on various aspects of the project. The authors are grateful to the FCO Chevening - HSBC Scholarship, Hansell Travel Grant and Discretionary Grant from Somerville College (Oxford), Dissertation grant of SoGE, the Raptor Research and Conservation Foundation (Mumbai), the Government of India's Ministry of Environment, Forest and Climate Change, and the University of Oxford (Felix Scholarship Trust) for funding. Delhi Police, the Forest Departments of Delhi and Uttar Pradesh, and the municipal corporations and civic bodies of the Government of NCT, Delhi, helped with legal permits. Members of the "Black Kite Project Group," especially Laxmi Narayan, Prince Kumar, Poonam, Zehen, Amee, Yukti, A Singh, P Kumar, H Malhotra, and G Singh helped in the fieldwork. Delhites extended enthusiastic participation and support, along with the important insights.

\section{REFERENCES}

1. Smil, V. 2013. Harvesting the Biosphere: What We Have Taken From Nature. Cambridge, MA: MIT Press.

2. Galushin, V. M. 1971. A huge urban population of birds of prey in Delhi India. Ibis 113:522. doi: 10.1111/j.1474-919X.1971.tb05189.x

3. Kumar, N., Gupta, U., Jhala, Y. V., Qureshi, Q., Gosler, A. G., and Sergio, F. 2018. Habitat selection by an avian top predator in the tropical megacity of Delhi: human activities and socio-religious practices as prey-facilitating tools. Urban Ecosyst. 21:339-49. doi: 10.1007/s11252-017-0716-8

4. Pinault, D. 2008. "Raw meat skyward: pariah-kite rituals in Lahore," in Comparative Islamic Studies: Notes From the Fortune-Telling Parrot: Islam and the Struggle for Religious Pluralism in Pakistan, ed D. Pinault (Bristol: Equinox Publishing Ltd). p. 108-21.

5. Anonymous. 2016. Rise of the city. Science 352:906-7. doi: $10.1126 /$ science. 352.6288 .906

6. Sharan, A. 2014. In the City, Out of Place: Nuisance, Pollution, and Dwelling in Delhi, c. 1850-2000. Oxford: Oxford University Press.

SUBMITTED: 23 July 2019; ACCEPTED: 25 March 2020;

PUBLISHED ONLINE: 22 April 2020.

EDITED BY: Becky Louize Thomas, University of London, United Kingdom

CITATION: Kumar N, Gupta U, Jhala YV, Qureshi Q, Gosler AG and Sergio F (2020) Cities: How Do Some Birds Thrive There? Front. Young Minds 8:46. doi: 10.3389/ frym.2020.00046 
CONFLICT OF INTEREST: The authors declare that the research was conducted in the absence of any commercial or financial relationships that could be construed as a potential conflict of interest.

COPYRIGHT () 2020 Kumar, Gupta, Jhala, Qureshi, Gosler and Sergio. This is an open-access article distributed under the terms of the Creative Commons Attribution License (CC BY). The use, distribution or reproduction in other forums is permitted, provided the original author(s) and the copyright owner(s) are credited and that the original publication in this journal is cited, in accordance with accepted academic practice. No use, distribution or reproduction is permitted which does not comply with these terms.

\section{YOUNG REVIEWER}

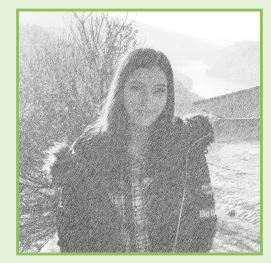

\section{LUANA, AGE: 14}

I like to roller skating, ride a bike, watch movies, and hang out with my friends.

\section{AUTHORS}

\section{NISHANT KUMAR}

Nishant is a researcher jointly based at the Department of Zoology (University of Oxford) and the Wildlife Institute of India. In Delhi, he tries to understand opportunistic animal responses to resources provided by humans, and how centuries of coexistence have tied urban ecology of commensals with religiously founded patronage and ritual animal feeding by people. He is currently interested in understanding the socio-economic impacts of scavenging ecosystem services provided by opportunistic commensals and how their biocultural links are vital for a sustainable urban future in South Asia. *nishant.kumar@zoo.ox.ac.uk; ryu.nishant@gmail.com

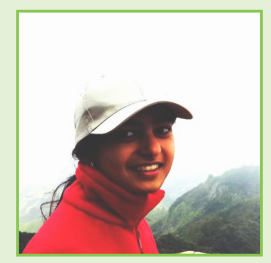

\section{URVI GUPTA}

A wildlife enthusiast since childhood, Urvi is the Project Biologist at the Wildlife Institute of India and leads the Black Kite Project. A traveler who likes to see new places, nature-reserves and cultures, Urvi has always been an environmentalist, exemplifying carpooling, waste reduction and minimalism to influence family and friends to live sustainably. Having a background in Zoology from Delhi University and a Masters in Biodiversity, Conservation and Management from Oxford as a Chevening Scholar, she hopes to bridge the gaps between disciplines for wildlife conservation. She is interested in conservation, evolutionary ecology, human-animal interactions and science communication.

\section{YADVENDRADEV V. JHALA}

Yadvendradev is a carnivore biologist based at the Wildlife Institute of India. He has been passionate about animals and wilderness since his childhood and wanted to become a zookeeper. His current interest domain covers population ecology, behavioral ecology, and conservation biology and genetics. He leads multiple research programs on the predator-prey dynamics within the Indian protected area network, e.g., the tiger and its prey, and Asiatic Lions. He is also leading the Great 

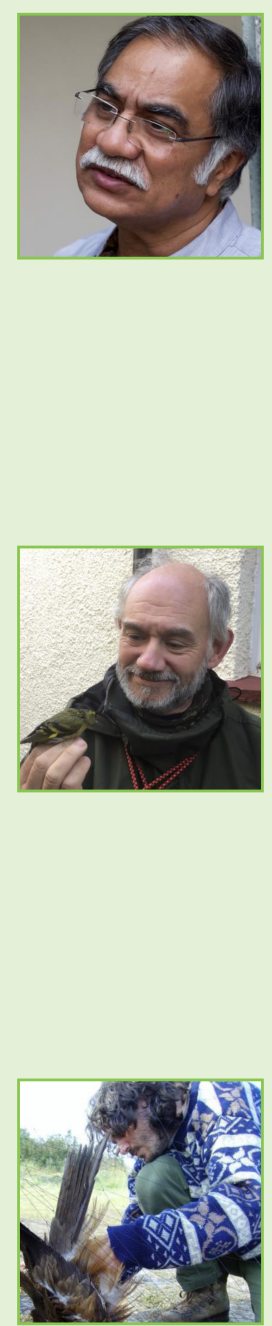

Indian Bustard conservation breeding program and is involved in the countrywide estimation and monitoring of the tiger and its prey species.

\section{QAMAR QURESHI}

At the Wildlife Institute of India, Qamar jointly leads the famed All India Tiger Monitoring Project with Yadvendradev. With expertise in landscape ecological methods, he has worked on habitat use patterns using remote sensing and GIS. $\mathrm{He}$ is currently involved with projects dealing with biodiversity assessment at the landscape levels. He leads the research on Gangetic Dolphin, working throughout rivers Ganges and Brahmaputra. He also works on rhesus macaques, blue bulls, and wild pigs to understand the human-animal interactions and conflicts. Besides wildlife research, Qamar is an avid reader with a wide taste that he considers essential for every science enthusiast.

\section{ANDREW G. GOSLER}

Andy researches questions in Ornithology and Ethno-ornithology concerning Nature Conservation in the broadest terms. He holds a joint position between the Zoology and Anthropology departments at the University of Oxford. He studied the Great Tit population of Wytham Woods and how finely tuned adaptations of the birds fitted them to their ecological community. This work has also contributed to environmental monitoring and conservation. His work now is focused on the significance of birds in engaging people with nature, both for their benefit and the benefit of wildlife, and helping people to understand how their dependence on nature means they must protect nature.

\section{FABRIZIO SERGIO}

A book gifted by his father, based on the tigers of Ranthambore National Park-India, catalyzed Fabrizio's childhood passion for wildlife. He is based at Doñana Biological Station-CSIC, Spain. He has researched several diurnal and nocturnal raptor species, with a special interest in species interactions, climate change and demography. 